least have a 'health policing' role, something that it currently lacks.

The reporting of avian-flu cases has recently improved in speed and openness, but the quality of the available data remains dire, and biological samples are insufficient. A typical WHO update will give the number of new cases from a country and, on a good day, the age, sex and rough location of each case. But there is little information on familial case clusters, and typically no clinical data. What is worse, these few data are in text form strewn across hundreds of individual WHO web pages.

Data on outbreaks in poultry are even more sparse, and mostly come from the World Organisation for Animal Health (OIE). Someone at the UN Food and Agriculture Organization (FAO) is maintaining a file of cumulative bird outbreaks from OIE and other data, and is making it available to researchers and journalists. But it is incomplete, lacks good location data and contains errors.

Genetic data are also lacking. When samples are sequenced, the results are usually either restricted by governments or kept private to an old-boy network of researchers linked to the WHO, the US Centers for Disease Control and Prevention, and the FAO. This is a far cry from the Human Genome Project, in which all the data were placed in the public domain 24 hours after sequencing. Many scientists and organizations are also hoarding sequence data, often for years, so they can be the first to publish in academic journals. With the world facing a possible pandemic, such practices are wholly unacceptable. Nature and its associated journals are not alone in supporting the rapid prior exposure of data when there are acute public-health necessities.
Three cheers, then, to Ilaria Capua of the Tri-Veneto Region Experimental Animal Health Care Institute in Italy, who last month threw down the gauntlet to her colleagues by refusing to put her latest data on Nigeria and Italy in these private networks. Instead she uploaded them to GenBank and called on her colleagues worldwide to do likewise. Only in this way can researchers establish and track the global pattern of the evolution of the bird-flu virus.

Imagine scientists anywhere being able to log on to a publidy available, searchable Internet database, updated in real time, with full clinical and sequence data on each human case, and accurate and complete poultry
"The world badly needs a database for outbreaks of avian flu." data. Dream on. The WHO's dunky online Global Health Atlas, which gives rough aggregate data for many diseases, doesn't have a category for $\mathrm{H} 5 \mathrm{~N} 1 \mathrm{under}$ influenza. The Global Infectious Diseases Epidemiology Online Network (GIDEON) database contains only the data on avian flu that it extracts from the WHO's updates and reports from the ProMED reporting system for infectious diseases. ProMED itself has pioneered outbreak alerting, notably during the SARS crisis, but its content consists largely of media cuttings. Such aggregation is often done faster and better by bloggers, and by the Global Public Health Intelligence Network (GPHIN), a Canadian intelligence operation that provides an early warning system that screens media and blogs in seven languages in real time.

The world badly needs a database for outbreaks of avian flu. But international agencies are failing to rise to the challenge.

\section{The right chemistry}

\section{Nature celebrates a discipline's unheralded achievements.}

7 elevision and cinema aren't often kind to chemists, who regularly find themselves portrayed as the nefarious creators of toxic pollutants, or as mad scientists brewing up Love Potion \#9 in some cluttered and archaic laboratory.

But most chemists innocently pass their time trying to figure out how things work at the molecular level, often using a relatively simple set of concepts to shed light on complex natural phenomena.

Fireflies, for example, communicate with each other by emitting light, and the protein responsible for this bioluminescence reaction is luciferase, which is well known to biologists. In this issue of Nature, Nakatsu and co-workers explain how they used synthetic chemistry, structural biology and biochemistry to explore how changes in the active site of the protein lead to changes in the colour of the emitted light (see pages 285 and 372).

The work is published as part of an issue in which we have collected, ahead of the American Chemical Society's meeting in Atlanta, Georgia, several chemistry and biochemistry papers along with an interview with Nobel laureate Roald Hoffmann on his work with young scientists in the Middle East (see page 274) and a NatureJobs assessment of career opportunities in green chemistry (see page 378).

In addition, Nature's website now includes a collection of recently

published Nature papers on metalloproteins, a set of proteins containing transition metals that are involved in a wide range of biologically significant processes, including DNA repair and the biosynthesis of natural products (see www.nature.com/nature/ focus/metalloproteins).

Our website also features a chemistry blog launched this week, 'The Sceptical Chymist', featuring entries by editors at Nature journals as well as by authors and readers (see http://blogs.nature.com/ thescepticalchymist). The first blog entry explains the choice of title.

Last, but not least, the website will feature a podcast including lively interviews about chemistry and biochemistry papers recently published in Nature and its sister journals. The podcast and an online collection of recent chemistry content will be

"We hope that this modest
barrage of publishing
activity will help to convey
some of the excitement
tothe wider scientific
community."
available from $23 \mathrm{March}$ (see www.nature.com/conferences/acs).

Chemists themselves probably don't need to be reminded of the usefulness of their work, or of the excitement inherent in it. We hope, however, that this modest barrage of publishing activity will help to convey some of that excitement to the wider scientific community - and even to interested observers in the world beyond. Perhaps one day even Hollywood producers will recognize the diligence with which chemists attempt to interrogate nature, and the inherent value of their contribution to our understanding of it. But don't hold your breath. 